\title{
Manganese Mutagenesis in Yeast. A Practical Application of Manganese for the Induction of Mitochondrial Antibiotic-resistant Mutations
}

\author{
By ALEKSANDRA PUTRAMENT, HANNA BARANOWSKA, \\ ANNA EJCHART AND WIESLAWA PRAZMO \\ Department of Genetics, Institute of Biochemistry and Biophysics, \\ Polish Academy of Sciences, Warsaw, Poland
}

(Received 3 February 1975; revised 28 April 1975)

\begin{abstract}
SUMMARY
When yeast cells were incubated for 4 to $8 \mathrm{~h}$ in yeast extract-peptone-glucose medium, pH 6, containing $8 \mathrm{~mm}$-manganese, and then plated on selective media, there was a strong induction of antibiotic-resistant mutations. Indirect evidence suggests that practically all resistant mutants selected were of independent origin. The analysis of manganese-induced resistant mutants showed that most were extranuclear, while those tested showed recombination with known mitochondrial markers.

Our results suggest that manganese can be considered as a mutagen which specifically induces mitochondrial mutations in Saccharomyces cerevisiae.
\end{abstract}

\section{INTRODUCTION}

In studies of nucleus-cytoplasm interactions, and mitochondrial genetics in particular, it is important to determine whether the mutations are in nuclear or mitochondrial DNA. Phenotypically similar point mutations leading to drug resistance can occur in either (Wilkie, 1968; Avner \& Griffiths, 1973a, b). It would therefore be useful to find mutagens inducing predominantly nuclear, or predominantly mitochondrial, mutations. The number of factors capable of inducing nuclear mutations is practically unlimited and at least one of them, nitrosoguanidine (Dawes \& Carter, 1974) is also capable of the efficient induction of antibiotic-resistant mutations in mitochondrial DNA (mitDNA). On the other hand, manganese is apparently the only known mutagen which is weakly mutagenic with respect to nuclear genes (Puglisi, Lucchini \& Vecli, 1970; Putrament, Baranowska \& Prazmo, I973), but efficient in inducing mitochondrial antibiotic-resistant mutations in yeast.

The purpose of the present work was to find conditions which would allow induction by manganese of mitochondrial $\mathrm{Ant}^{\mathrm{R}}$ (antibiotic-resistant) mutations of independent origin, without concomitant induction of cytoplasmic petite (rho-) mutations and gross changes in yeast cell populations.

\section{METHODS}

The strains of Saccharomyces cerevisiae used are described in Table I.

Media. YEPGlu contained I \% yeast extract, I \% peptone, $2 \%$ glucose; YEPGlyc was YEPGlu with $2 \%$ glycerol instead of glucose. The YEPGlyc medium with $0 \cdot \mathrm{I} M$ (final concentration) phosphate buffer, $\mathrm{pH} 6.2$, and $0.5 \%$ erythromycin or $0.4 \%$ chloramphenicol or $3 \mu \mathrm{g}$ oligomycin/ml was used to select Ant ${ }^{\mathrm{B}}$ mutants. YEPdif was YEPGlyc 


\section{Table 1. Yeast strains}

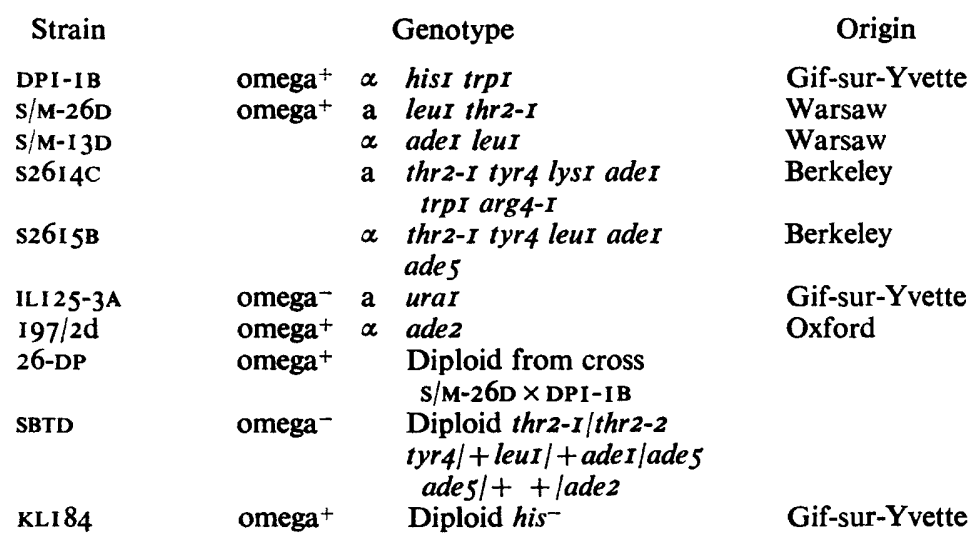

with $0.2 \%$ glucose added. On this medium, respiratory-deficient and respiratory-sufficient colonies were distinguished. Minimal medium contained $0.67 \%$ yeast nitrogen base without amino acids but with $2 \%$ glucose, and was used for selecting diploids and testing nutritional requirements.

Mutagenesis. In all experiments the cells to be used as inocula were pre-grown to stationary phase in YEPGlyc liquid medium and stored at least overnight in a refrigerator. All data presented here were obtained by adding $\mathrm{MnCl}_{2}$ or $\mathrm{MnSO}_{4}$ to $\mathrm{YEPGlu}$ medium, with $\mathrm{pH}$ adjusted to 6 , to a final concentration of $8 \mathrm{~mm}$; this medium will be referred to as the mutagenic medium. To $10 \mathrm{ml}$ of this medium cells were added to a final density of about $5 \times 10^{5} / \mathrm{ml}$, and incubated on a shaker at $30^{\circ} \mathrm{C}$ for the periods indicated in the legends to Fig. I and Tables I, 2 and 3. In each experiment in which the effects of different periods of mutagenic treatment or plating conditions were compared, the cells were incubated in a single flask from which $10 \mathrm{ml}$ samples were taken. Thus the effects of post-treatment could be compared in samples of cells which had been identically mutagenized. From Io ml samples the cells were collected by centrifuging and either resuspended in a smaller volume of the mutagenic medium, or washed and resuspended as indicated. Volumes $\left(0.1 \mathrm{ml}\right.$, containing $2 \times 10^{5}$ to $8 \times 10^{5}$ cells) were plated on antibiotic-containing

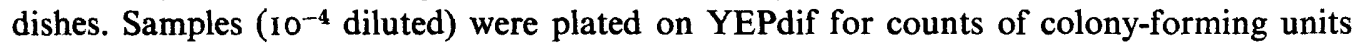
(c.f.u.) and rho- estimation. $\mathrm{E}^{\mathrm{R}}$ and $\mathrm{O}^{\mathrm{R}}$ (erythromycin- and oligomycin-resistant) mutant colonies were counted after ro days of incubation, and $\mathrm{C}^{\mathrm{R}}$ (chloramphenicol-resistant) after 14 days.

Sporulation and tetrad analysis of 26-DP $\mathrm{O}^{\mathrm{R}}$ mutants were performed routinely.

Mitotic segregation of $197 / 2 \mathrm{~d} \mathrm{E}^{\mathrm{R}}$ mutants was carried out by the standard cross technique as described by Coen et al. (1970).

Chemicals. Erythromycin and chloramphenicol (trade name Detreomycyna) were Polfa products. $\mathrm{MnCl}_{2}$ and $\mathrm{MnSO}_{4}$ were of analytical grade. Yeast extract and casein hydrolysate were either Difco or Polish products (Autolizat drożdżowy, produced by Wytwórnia Surowic i Szczepionek, and Peptobak, produced by Bacutil, respectively). 


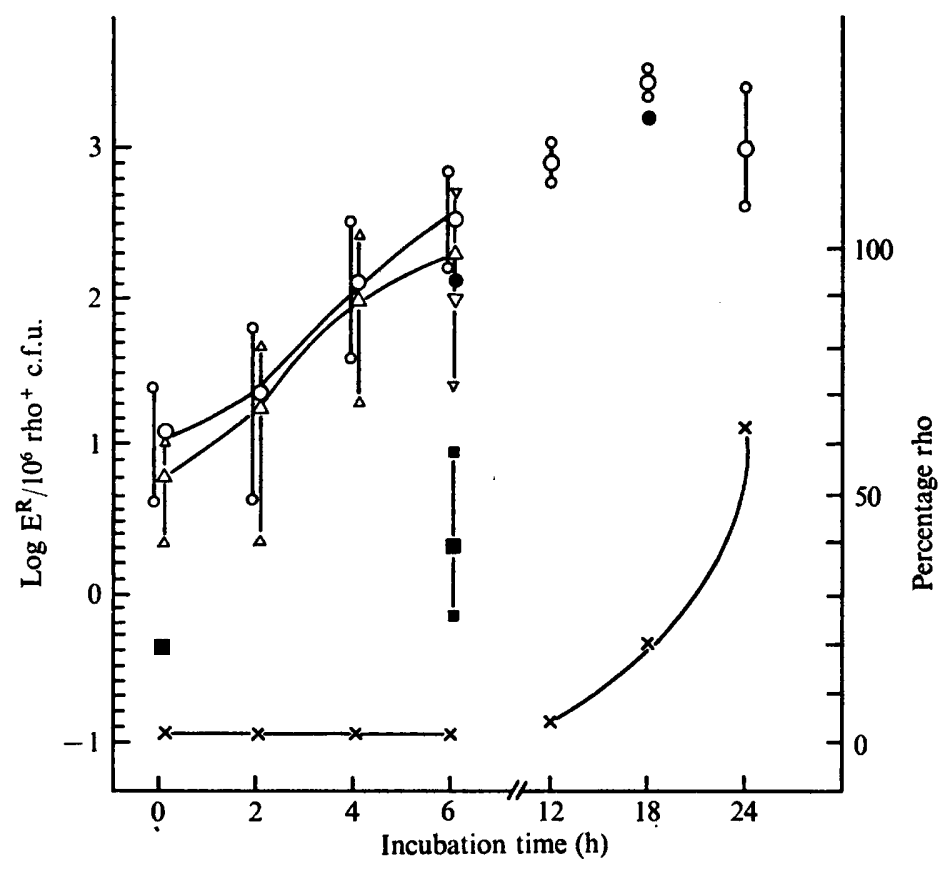

Fig. I. Induction by manganese of $\mathrm{E}^{\mathrm{R}}$ mutations in strain 26-DP after different periods of incubation in the mutagenic medium. The points for 0 to $6 \mathrm{~h}$ incubation in the mutagenic medium represent mean values from five experiments. The lowest and highest frequencies obtained are marked by vertical bars. The $E^{\mathrm{R}}$ frequencies after 12,18 and $24 \mathrm{~h}$ represent mean values from 2, 3 and 4 experiments, respectively. The spontaneous mutation frequencies in stationary cells varied from 0.34 to $1.4 / 10^{6} \mathrm{rho}^{+}$c.f.u., while those in exponentially-growing cells varied from $\mathrm{I} \times 10^{-6}$ to $4 \times 10^{-6}$ in four experiments, and were $0.7 \times 10^{-8}$ and $9 \times 10^{-6}$ in two other experiments, respectively. Higher $\mathrm{E}^{\mathrm{R}}$ frequencies in exponentially-growing cells could be spurious, owing to the fact that in stationary phase the c.f.u. consisted of single cells, while in exponential phase the c.f.u. consisted of I, 2 or even 3 cells. In experiments with 0 to $2 \mathrm{~h}$ mutagenesis, the number of $E^{\mathrm{R}}$ mutants varied from Io to 100 , thus decreasing the reliability of the data. In all other experiments they were one to several hundred.

Plating in: $O$, mutagenic or standard YEPGlu medium; $O$, YEPdif; $\nabla$, saline; $\triangle$, Ringer solution; $\mathbf{a}$, control (plated in YEPGlyc or YEPGlu); $\times$, percentage rho-.

\section{RESULTS AND DISCUSSION}

Induction of Ant $^{\mathrm{R}}$ mutants

Preliminary experiments suggested that the total yields of $\mathrm{Ant}^{\mathrm{R}}$ mutants induced and/or recovered depend on several factors such as manganese concentration, $\mathrm{pH}$ of the mutagenic medium, inoculum size, conditions of plating on the antibiotic-containing medium, and the properties, probably genetic, of the strains tested. It was impossible to estimate with any degree of accuracy the role played by each of these factors in the final yields of the Ant $^{\mathrm{R}}$ mutants, because these yields varied considerably even in identically performed experiments (cf. Demerec \& Hanson, 195I).

As seen in Fig. I, up to $2 \mathrm{~h}$ exposure to the mutagenic medium led to very slight if any increase of the frequencies of $\mathrm{E}^{\mathrm{R}}$ mutants in strain 26-DP. But after 4 and $6 \mathrm{~h}$ incubation induction of $\mathrm{E}^{\mathrm{R}}$ mutants was always observed. During the $6 \mathrm{~h}$ period starting with stationary-phase cells, the cells in control cultures underwent two to three divisions, while those in the mutagenic medium divided once or twice. Incubation of both this and the other 


\section{Table 2. Induction by manganese of $E^{\mathbb{R}}$ mutations after $8 \mathrm{~h}$ treatment of different strains}

The cells of all strains were mutagenized for $8 \mathrm{~h}$ as described in Methods. The data are the means of two experiments for strains I97/2d, KLI84 and SBTD, and the results from single experiments for the remaining strains. The control involved exponentially-growing organisms.

\begin{tabular}{|c|c|c|c|c|c|c|c|c|c|}
\hline \multirow{2}{*}{$\begin{array}{l}\text { Before plating, cells } \\
\text { resuspended in: }\end{array}$} & \multicolumn{9}{|c|}{$\mathrm{E}^{\mathrm{R}}$ mutants $/ 10^{6}$ rho ${ }^{+}$c.f.u. } \\
\hline & S/M-I3D & $s / M-26 D$ & DPI-I B & ILI 25-3A & $197 / 2 d$ & $\mathrm{~s} 26 \mathrm{I} 4 \mathrm{C}$ & S2615B & KLI 84 & SBTD \\
\hline Mn medium & 112 & 20 & 50 & 38 & 155 & 308 & 88 & 82 & 33 \\
\hline YEPGlu & - & 19 & 91 & - & 117 & - & - & - & - \\
\hline Ringer solution & - & $1 \cdot 5$ & 35 & 26 & 33 & 一 & 一 & 一 & - \\
\hline YEPdif* & 14 & 一 & - & 20 & 17 & 46 & 3.4 & 12 & 0.4 \\
\hline Control & 0.4 & $3 \cdot 0$ & $1 \cdot 0$ & $1 \cdot 0$ & $2 \cdot 0$ & $5 \cdot 5$ & 0.1 & 0.03 & 0.04 \\
\hline
\end{tabular}

tested strains in mutagenic medium for up to $8 \mathrm{~h}$ did not induce cytoplasmic petite (rho-) mutations.

Total yields of $E^{R}$ and $C^{R}$ mutants in strain 26-DP reached a maximum after $I^{8} \mathrm{~h}$ incubation in the mutagenic medium ( 3 to 4 cell divisions), and then underwent a gradual decrease with concomitant increase of the rho- mutations. Since not only the frequencies but also the absolute numbers of $\mathrm{E}^{\mathrm{R}}$ mutants per $\mathrm{ml}$ of the medium decreased during the 18 to $24 \mathrm{~h}$ period of incubation, it can be assumed that some potential $\mathrm{E}^{\mathrm{R}}$ mutants were converted into rho-. The percentage of rho- mutations was smaller than that indicated in Fig. I when the $\mathrm{pH}$ of the mutagenic medium was 6.7. In strain DPI-IB after $24 \mathrm{~h}$ incubation in the mutagenic medium at $\mathrm{pH} 6.5$, there was only very weak if any induction of rho- mutants, while this was very strong in the similarly treated s/M-26D strain. Thus, in this respect the diploid 26-DP behaved very much as its haploid component s/M-26D.

Eight hours' incubation in the mutagenic medium at $\mathrm{pH} 6$ led to pronounced induction of $\mathrm{E}^{\mathrm{R}}$ mutations in all strains tested (Table 2), although in strains S/M-26D and DPI-IB practically no induction was observed even after $\mathrm{I} 2 \mathrm{~h}$ incubation when the $\mathrm{pH}$ of the mutagenic medium was $6 \cdot 5$. The total yields of the $E^{\mathfrak{R}}$ mutants recovered were highest when, after mutagenesis, the cells were resuspended in the mutagenic medium or in the YEPGlu medium before plating on the erythromycin-containing agar. Lower yields were obtained when the cells were washed and resuspended in YEPdif, saline $(0.85 \%, \mathrm{v} / \mathrm{v}, \mathrm{NaCl})$ or Ringer solution. It might be expected that the mutagenized cells, incubated for $30 \mathrm{~min}$ in YEPdif medium before selective plating, would have favourable conditions for phenotypic expression of the $\mathrm{E}^{\mathrm{R}}$ mutations. However, as may be judged by the relatively small yields of $E^{R}$ mutants recovered (Fig. I and Table 2), such enhancement was not detected.

In a few experiments it was found that $6 \mathrm{~h}$ incubation of strain 26-DP in the mutagenic medium at $\mathrm{pH} 6$ led also to induction of $\mathrm{C}^{\mathrm{R}}$ and $\mathrm{O}^{\mathrm{R}}$ mutations.

\section{Characteristics of Ant, ${ }^{\mathbb{R}}$ mutants}

When the mutagenized cells were incubated for $3 \mathrm{~h}$ in YEPdif medium before plating, the total numbers of c.f.u. about doubled, the frequencies of $E^{R}$ mutants decreased by half, and the total number of potential $E^{\mathrm{R}}$ cells remained practically unchanged (Table 3 ). Thus, either the cells carrying $\mathrm{E}^{\mathbf{R}}$ mutations had lower division rates compared with the average cell population, or they divided at the same rate but only one of the two descendant 


\section{Table 3. Dilution of $E^{\mathrm{R}}$ mutant cells in strain 26-DP after $3 h$ incubation in YEPdif medium}

The cells were incubated in the mutagenic medium for $6 \mathrm{~h}$ as described in Methods. In parallel with washing and plating cells resuspended in YEPdif, the cells from the same mutagenized cultures were plated either without washing (i.e. suspended in the mutagenic medium), or following washing and resuspension in saline. The mean frequencies of $E^{R}$ mutants recovered were 365 and $96 / 10^{6}$ c.f.u., respectively.

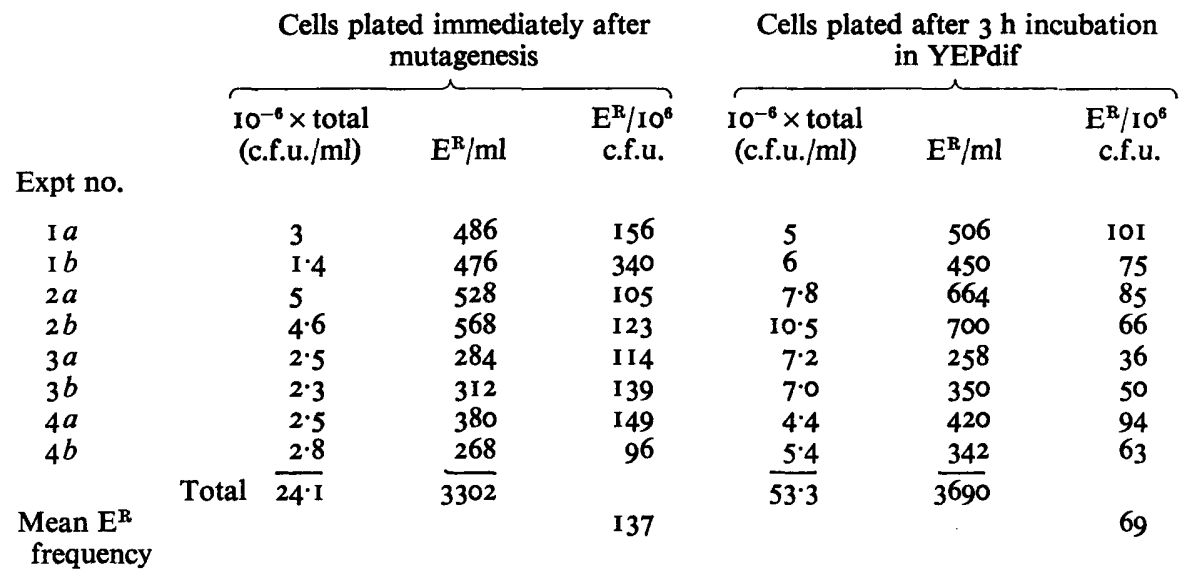

cells carried the $\mathrm{E}^{\mathrm{R}}$ mutation. In view of our earlier data (Putrament et al. 1973) and those of Birky (1973), the second alternative seems to be more probable. In any case our present data suggest strongly that, in a sample of mitochondrial Ant ${ }^{\mathbb{R}}$ mutants obtained after short treatment with manganese, each resistant colony represents an independent mutagenic event.

In all our experiments the new $\mathrm{E}^{\mathrm{R}}$ colonies appeared on the antibiotic-containing medium between the 4th and roth day of incubation, as was the case in both our earlier experiments (Putrament et al. 1973) and those described by Birky (1973) and by Dawes \& Carter (1974). It was suggested by Birky and by us that the prolonged appearance of the $E^{R}$ colonies on the selective medium may be due to non-identical numbers of mutant mitDNA molecules in different cells: those with higher numbers of mitDNA molecules carrying $\mathrm{E}^{\mathrm{B}}$ mutation could form colonies earlier than the cells carrying only one such molecule at the time of plating. However, it does not seem likely that among the cells in which $\mathrm{E}^{\mathrm{R}}$ mutations were induced during $6 \mathrm{~h}$ incubation in the mutagenic medium there could be big differences in the numbers of mitDNA molecules carrying $\mathrm{E}^{\mathrm{R}}$ mutation, while it is highly unlikely that such differences could exist at all when $\mathrm{E}^{\mathbf{R}}$ mutations were induced with nitrosoguanidine (Dawes \& Carter, 1974). Therefore, we supposed that the lateappearing $\mathrm{E}^{\mathrm{R}}$ mutants carried mutations conferring a lower degree of resistance than those of early-appearing colonies. Thus, ten early- and ten late-appearing $\mathrm{E}^{\mathrm{R}}$ mutants of strain 26-DP were tested for growth rate in liquid-buffered YEPGlyc medium containing $5 \mathrm{mg}$ erythromycin $/ \mathrm{ml}$, starting with identical inocula. Judging from turbidity measurements at $700 \mathrm{~nm}$ all $\mathrm{E}^{\mathrm{R}}$ mutants tested had identical growth rates, implying that they did not differ significantly in the level of erythromycin resistance. Thus, another explanation is required to explain why, in contrast to established resistant cells, the new resistant colonies, either of spontaneous origin (Birky, 1973) or induced by nitrosoguanidine (Dawes \& Carter, 1974) or with manganese (these data), continue to appear for several days. 
To check if manganese-induced $\mathrm{Ant}^{\mathrm{R}}$ mutants are indeed predominantly extranuclear, I3 manganese-induced $\mathrm{O}^{\mathrm{R}}$ mutants of strain 26-DP were sporulated. Only one gave 2:2 segregation whereas all the spores in the tetrads from the other 12 were resistant. Twentyfive $E^{R}$ mutants induced with manganese in strain $197 / 2 d$ were crossed with tester strains 55R5-3C, 55R 5-3C/32I or ILI87-4A/32 I (the latter two strains carrying a mitochondrial $\mathrm{C}^{\mathrm{R}}$ marker) and standard cross analysis (Coen et al. 1970) was performed. All $\mathrm{E}^{\mathrm{R}}$ mutants tested showed mitotic segregation into $E^{R}$ and $E^{\mathbf{s}}$. Five $E^{R}$ mutants were additionally analysed for recombination between $\mathrm{C}^{\mathrm{R}}$ and $\mathrm{E}^{\mathrm{R}}$ mitochondrial markers. The percentages of doubly-resistant recombinants in three crosses with ILI87-4A/32I were 6,8 and I4 respectively, while in two crosses with 55R5-3C/32I they were 0 and 0.3 respectively. Thus, strain $197 / 2 \mathrm{~d}$ can be classified as omega ${ }^{+}$. Similar results, suggesting predominantly mitochondrial Ant ${ }^{\mathrm{R}}$ mutants, were obtained after manganese mutagenesis in another laboratory by G. Kergastel, A. Touze and A. Nicolas (P. P. Slonimski and L. Clavillier, personal communication).

These data are in striking contrast with those concerning $\mathrm{C}^{\mathrm{R}}, \mathrm{E}^{\mathrm{R}}$ and $\mathrm{O}^{\mathrm{R}}$ mutants isolated from ultraviolet-irradiated cells (Wilkie, 1968; Avner \& Griffiths, 1973a,b), in which about $50 \%$ of the $A_{n}{ }^{\mathrm{R}}$ mutants tested showed either 2:2 segregation in meiosis or absence of mitotic segregation, and were accordingly classified as nuclear rather than mitochondrial mutations.

This work was supported by the Polish Academy of Sciences within project 0.9.3.I. and in part by PHS grant No. 05-00I-0. We are very grateful to Professor P. P. Slonimski for helpful criticism.

\section{REFERENCES}

AVNER, P. R. \& Griffiths, D. E. (1973a). Studies on energy-linked reactions. Isolation and characterisation of oligomycin-resistant mutants of Saccharomyces cerevisiae. European Journal of Biochemistry 32, 30I-3II.

AVNer, P. R. \& Griffirhs, D. E. (1973b). Studies on energy-linked reactions. Genetic analysis of oligomycin-resistant mutants of Saccharomyces cerevisiae. European Journal of Biochemistry 32, 31 2-321.

BIRKY, C. W. (1973). On the origin of mitochondrial mutants. Evidence for intracellular selection of mitochondria in the origin of antibiotic-resistant cells in yeast. Genetics 74, 42I-432.

Coen, D., Deutsch, J., Netter, P., Petrochilo, E. \& Slonimski, P. P. (1970). Mitochondrial genetics. I. Methodology and phenomenology. Symposia of the Society for Experimental Biology 24, 449.

DAwES, I. W. \& CARTER, B. L. A. (1974). Nitrosoguanidine mutagenesis during nuclear and mitochondrial gene replication. Nature, London 250, 709-712.

Demerec, M. \& HANSON, J. (195I). Mutagenic action of manganous chloride. Cold Spring Harbor Symposia on Quantitative Biology 16, 21 5-228.

Puglisi, P. P., Lucchin,, G. \& Vecl, A. (1970). Resistenze allo ione manganoso $\mathrm{Mn}^{2+}$ in Saccharomyces cerevisiae. Atti Associazione genetica italiana 15, I59-I 70.

Putrament, A., Baranowska, H. \& Prażmo, W. (1973). Induction by manganese of mitochondrial antibiotic resistance mutations in yeast. Molecular and General Genetics 126, 357-366.

Wrikre, D. (1968). Mutants of the respiratory system of yeast in problems of mitochondrial biogenesis. In Biochemical Aspects of Mitochondrial Biogenesis, pp. 457-468. Edited by E. C. Slater, J. M. Tager, S. Papa \& E. Quagliariello. Adriatica Editice. 